REVISTA DE DERECHo UNED, NÚM. 7, 2010

\title{
LA LIBERTAD RELIGIOSA DE LOS ANTIGUOS Y LA LIBERTAD RELIGIOSA DE LOS MODERNOS
}

\author{
JOSÉ MARÍA COELLO DE PORTUGAL \\ Doctor en Derecho \\ Profesor Ayudante de Derecho Constitucional \\ Universidad Complutense de Madrid
}

Title: Religious freedom of the ancients and religious freedom of the moderns.

Resumen: En el presente trabajo, a través de la clásica distinción de Benjamin Constant entre la libertad de los antiguos y la libertad de los modernos, se estudia la evolución del derecho a la libertad religiosa desde la antigüedad hasta el mundo contemporáneo, analizando cómo el contenido sustancial de este derecho se ha transformado desde el periodo del absolutismo hacia el Estado liberal y, posteriormente, hacia el constitucionalismo contemporáneo, produciendo numerosos equívocos acerca de su variable contenido. De otro lado, recuperando las ideas de Constant, se procura dar soluciones a los problemas de reciente aparición que el crecientemente globalizado mundo del siglo XXI ha generado al constitucionalismo en materia de libertad religiosa.

Palabras Clave: Libertad religiosa. Razón de Estado. Laicidad. Laicismo. Globalización.

Abstract: In this paper, through Benjamin Constant s classic distinction between freedom of the ancients and freedom of the moderns, we study the evolution of the right to religious freedom from antiquity to the modern world by analyzing how the substantial content of this right has been transformed since the period of absolutism to the liberal State and, subsequently, to the contemporary constitutionalism, causing many misunderstandings about its variable content. On the other hand, taking the ideas of Constant, is intended to provide solutions to emerging issues about the right to religious fre- 
edom that the increasingly globalized world of the XXI century has generated to constitutionalism.

Key Words: Religious freedom. Reason of State. Laicity. Laicism. Globalization.

Sumario:I.- Las formas históricas de la libertad religiosa.II.- La libertad religiosa de los antiguos.III.- La paradoja de la razón de Estado: absolutización del Estado y absolutización de la religión.IV.La libertad religiosa de los modernos y el movimiento constitucional, o de cómo no hacer ni del Estado religión, ni de la religión Estado.

\section{I.- LAS FORMAS HISTÓRICAS DE LA LIBERTAD RELIGIOSA}

\section{Señores:}

Me propongo someter a su consideración algunas distinciones, todavía bastante nuevas, entre dos clases de libertad, cuyas diferencias han pasado inadvertidas hasta hoy, o al menos han sido muy poco destacadas. Una es la libertad que tanto apreciaban los pueblos antiguos; la otra es aquélla cuyo disfrute es especialmente valioso para las naciones modernas. Si no me equivoco, será interesante considerar esta indagación bajo un doble aspecto ${ }^{1}$.

Las anteriores palabras fueron pronunciadas en el mes de febrero de 1819 por un Benjamín Constant en plena madurez intelectual, que en el Ateneo de París alumbraba la que es, probablemente, la más famosa de sus reflexiones acerca de la libertad política. En aquella memorable alocución, lograba Constant parar los relojes de la historia del pensamiento político con la llamada de atención a sus contemporáneos sobre un hecho frecuentemente inadvertido: la diferencia cualitativamente insalvable entre la libertad política demandada por los hombres de antes y de después de la era de las Revoluciones y de la aparición del constitucionalismo.

Han existido en la Historia dos formas muy distintas de entender la libertad política aún hoy frecuentemente confundidas por algunos tratadistas. Una primera, la que Constant llamó libertad de los antiguos, basada en la conciencia colectiva y en la dignificación personal del hombre a través de su inclusión en un grupo, en el que la identi-

1 CONSTANT, Benjamin. «De la libertad de los antiguos comparada con la de los modernos» en Escritos Políticos. Ed. Centro de Estudios Constitucionales. Madrid, 1989. Pág. 257. 
dad comunitaria es el principal valor reconocido por la moral y protegido por el Derecho. Así, los antiguos construyeron una sociedad -sin duda difícil de entender para el hombre contemporáneo- cuya idea de libertad se cifraba en el reconocimiento orgánico del Derecho al particular estatuto de los grupos familiares, estamentales, gremiales y en general a todos los estamentos político-corporativos en que cada persona se encontraba inserta; y en cuya inserción encontraba su dignidad, su honor y, en definitiva, su libertad. Solo en este contexto se entiende la fascinación de los antiguos, personal y colectivamente, por conservar la puridad en sus identidades corporativas y en acreditar el arraigo de un linaje familiar, la vieja profesión de unas creencias religiosas, la vinculación por generaciones a una determinada localidad o poblamiento o al inmemorial desempeño de un arte u oficio, como inequívocos gestos de desprecio de lo individual y de exaltación de un espíritu corporativo.

Una segunda forma de entender la libertad, la que Constant denominará libertad de los modernos es la que nació con la era de las Revoluciones constitucionales junto con la nueva conciencia de individuo inherente al movimiento liberal-constitucional. La libertad de los modernos se configura así como una nueva libertad, de esencia individual e inherente a la dignidad de cada individuo en cuanto que tal, no mediatizada por la pertenencia de éste a un determinado cuerpo o grupo social de prestigio corporativo. Nueva idea de libertad política que encuentra en la pertenencia al grupo incluso una potencial amenaza a la libre determinación de este individuo donde antes residía su mejor garantía de honorificencia, es decir, en la agrupación familiar, religiosa, étnica, gremial o política en la que el individuo se

${ }^{2}$ CONSTANT señalará a propósito de esta libertad de los modernos que:

"Es el derecho de cada uno a no estar sometido más que a las leyes, a no poder ser ni arrestado, ni detenido, ni muerto, ni maltratado de manera alguna a causa de la voluntad arbitraria de uno o de varios individuos. Es el derecho de cada uno a expresar su opinión, a escoger su trabajo y a ejercerlo, a disponer de su propiedad, y abusar incluso de ella; a ir y venir sin pedir permiso y sin rendir cuentas de sus motivos o de sus pasos. Es el derecho de cada uno a reunirse con otras personas, sea para hablar de sus intereses, sea para profesar el culto que él y sus asociados prefieran, sea simplemente para llenar sus dias y sus horas de la manera más conforme a sus inclinaciones, a sus caprichos. Es, en fin, el derecho de cada uno a influir en la administración del gobierno, bien por medio del nombramiento de todos o de determinados funcionarios, bien a través de representaciones, de peticiones, de demandas que la autoridad está más o menos obligada a tomar en consideración».

CONSTANT, Benjamin. «De la libertad de los antiguos comparada con la de los modernos» en Escritos Políticos. Ed. Centro de Estudios Constitucionales. Madrid, 1989. Pág. 259. 
integraba ${ }^{2}$. La integración grupal, que era así para los hombres antiguos previa a la voluntad personal, nace para los hombres modernos estricta y exclusivamente, en cuanto la naturaleza de las cosas lo permite, del acto asociativo derivado de la voluntad individual y, por tanto, de la libre autodeterminación del sujeto. La libertad política de los antiguos exigía así la participación política, mediatizada por la inclusión en la corporación social que, a su vez, era parte en la toma de decisiones comunitarias. La libertad de los modernos demandará la nueva forma de participación del individuo a través de la representación política y del voto, y con él, de una cuota individual e intransferible del poder colectivo ejercitable por cada sujeto según su particular criterio en cada cuestión de trascendencia social.

Solo en un par de puntos permanece idéntico el sentido de libertad invocado por los antiguos y demandado por los modernos: en ambos casos el concepto de libertad se configura como un prius para la dignidad del hombre en sus respectivos siglos y en ambos se establece dogmáticamente -de ahí su frecuente confusión- un sistema participativo de la persona en el grupo político. Ocurre que es, precisamente, el alcance de esta participación, al igual que la forma de ejercerla, una de las insalvables diferencias entre ambas ideas de libertad: para los antiguos existe un deber moral, de participar en el orden político, mientras que para los modernos existe un derecho individual e inalienable a compartir ese poder político a través del mecanismo de la representación. Mientras que la arquitectura de la libertad antigua es netamente corporativa y se funda en la identidad del grupo, la arquitectura de la libertad moderna es esencialmente individualista y se funda en la libre determinación del sujeto y en el desarrollo de su propia personalidad. Quienes participaban de la libertad de los antiguos reiteraban con firmeza su condición de súbditos como paradójica garantía de su dignidad dentro de la comunidad humana, mientras que quienes disfrutamos de la libertad de los modernos, invocamos la condición de ciudadanos como estatuto activo de participación individual y de reconocimiento de derechos en la vida política y social, ejercidos directamente o por medio de representantes.

Como es notorio, ambas consideraciones de la libertad, la propia de los antiguos y la propia de los modernos, no han podido dejar indiferente a lo largo de la Historia a una de las más nucleares manifestaciones de la condición libre del hombre: su libertad religiosa. La forma de entender por antiguos y modernos la libertad de religión, es una de las facetas a través de las que mejor y más nítidamente se distingue el ejercicio de la libertad por los hombres de los tiempos anti- 
guos y modernos. La clásica distinción de Constant resulta hoy, sin embargo, con cierta frecuencia olvidada por los tratadistas al abordar los fenómenos político-religiosos históricos y contemporáneos, desconociendo o confundiendo los diversos sentidos y el diverso alcance para antiguos y modernos del concepto de libertad que Constant separara en 1819 y; por tanto, de los diversos sentidos que en el curso de la Historia tuvo la invocación de la libertad religiosa como faceta irreductible, para antiguos y modernos, de su libertad política.

\section{1.- Libertad antigua, libertad moderna; una clasificación, frecuentemente olvidada.}

Sin libertad religiosa, efectivamente, lo mismo para antiguos que para modernos, no existe libertad política. Parece tópico reiterar esta afirmación que resulta, sin embargo, más veces olvidada de hecho que reiterada de palabra y que, desde luego, permanece de plena vigencia en el contexto del Estado constitucional contemporáneo. Mas esta protección de la libertad religiosa, como faceta irreductible y exigencia apriorística de la libertad política, no es, como veremos, una creación del Estado constitucional postrevolucionario. Efectivamente, las viejas naciones de Europa conocieron el concepto de libertad religiosa mucho antes que el concepto de Constitución en un sentido revolucionario. Pocas veces se han afanado tanto los diplomáticos de media Europa en definir y formalizar la libertad religiosa y su concepto jurídico-normativo como durante las negociaciones que culminaron con la firma de la Paz de Augsburgo, allá en 1555, o tras la Guerra de los Treinta Años a la firma de los Tratados de Westfalia en 1648. El concepto de libertad religiosa es, por tanto, mucho más antiguo que el Estado constitucional. Ocurre, sin embargo, que esta libertad de religión demandada por los europeos del siglo XVII, respondía a un ideal de libertad basado en el lo que Constant llamara con nítida precisión «libertad de los antiguos». Libertad antigua que demandaba bajo el concepto de «libertad religiosa», paradójicamente, lo que hoy llamamos un Estado confesional intolerante; esto es, el reconocimiento y la protección jurídica no del individuo sino de la comunidad política para confesar colectivamente una religión, coincidente con el credo de su nuevo Príncipe soberano.

Como vemos, la innovación del Estado constitucional revolucionario se reduce en este punto a la modernización jurídica del concepto antiguo de libertad religiosa, que no se crea ex novo -como sucede con tantas otras libertades personales y patrimoniales hijas de la 
Revolución burguesa- sino que tan solo se recrea, de acuerdo con los postulados individualistas sentados por la Revolución y por el nuevo Estado constitucional.

El tránsito de la libertad religiosa de los antiguos a la libertad religiosa de los modernos, no obstante, no fue obra de un día, ni de una sola experiencia constitucional sino que supuso a través de un zigzagueante recorrido histórico, de un lado, la renuncia a la vieja aspiración de la confesionalidad estatal por parte de las diferentes confesiones religiosas y de otro, la asunción por parte del Estado constitucional de su neutralidad en materia religiosa. Proceso histórico que culmina con la consolidación del Estado constitucional contemporáneo y para cuya adecuada comprensión en este punto debemos partir en nuestro análisis, como en su día hiciera Constant, desde mucho más atrás, esto es, desde el análisis de la libertad religiosa de los hombres antiguos.

\section{II.- LA LIBERTAD RELIGIOSA DE LOS ANTIGUOS}

\section{1.- Secularización del poder político y libertad religiosa en la génesis del Estado.}

El Estado absoluto se configura en el occidente europeo como la primera estructura política potencialmente omnipotente y, por tanto, independiente de cualquier tutela espiritual en el seno de la convivencia occidental. La construcción política de este Estado y aún antes, la creación de su concepto de manos de Nicolás Maquiavelo responde, entre otros factores históricos determinantes, a una reacción frente a la organización política propia del Imperio medieval cristiano frente al poder de una religión universal. El largo período imperial cristiano, coincidente en su espíritu con el de la Edad Media, se había configurado de forma asistemática en las distintas regiones de Europa, durante un periodo de aproximadamente diez siglos que se inicia con la caída del Imperio Romano de Occidente y la aparición del Renacimiento y se extiende hasta la caída del Imperio bizantino o incluso, en opinión de algunos, con la definitiva consolidación de la Europa de las Monarquías nacionales a la firma de la Paz de Westfalia en 1648. Durante este asistemático período de más de mil años, el fenómeno homogeneizador de la estructura política occidental no es un único sistema político, ni económico, ni por supuesto jurídico. Muy al contrario, la principal, si no la única identidad cultural común en el Occidente europeo es, precisamente, la profesión de una Fe re- 
ligiosa común -de la misma manera que durante la etapa anterior lo había sido la extensión del Derecho Romano ${ }^{3}$ - hasta el punto de que Europa durante el medioevo, más que un concepto geográfico impermeable es un ideal político y un concepto cultural que alcanza, en un sentido amplio, hasta donde alcanzan las fronteras de la cristiandad.

La idea, el concepto mismo del Estado, nace así como una decidida reacción de ruptura contra el orden político cristiano medieval propio del agustinismo fundado en la doctrina política de las dos espadas $^{4}$ del cristianismo: el trono y el altar ${ }^{5}$, desafiados por vez primera por Nicolás Maquiavelo. Uno de los primeros rasgos que caracterizan así el nacimiento conceptual del Estado en la mente de su creador, varios siglos antes de su efectiva construcción histórica y política será, paradójicamente, su carácter secularizador respecto de los poderes universales de la Iglesia y del Papa. Ha tocado a su fin con el Renacimiento italiano el esplendor cultural de los ideales caballerescos medievales y el prestigio del otrora universal Imperio de la respublica christiana. Los avances de las ciencias exactas y naturales, la rápida difusión de las ideas, la apertura de nuevas vías de comunicación y de centros de investigación universitaria en los nuevos núcleos urbanos, habrán generado la coyuntura histórica para una definitiva crisis del orden político imperial diseñado por Agustín de Hipona bajo las dos únicas autoridades universales del Emperador y

3 «Pues para la latina Europa occidental y la Europa central, la especial importancia del Derecho romano ha consistido en haber llegado a ser el fundamento de una cultura jurídica unitaria. El Corpus Iuris Civilis ofreció el punto de partida para una ciencia del Derecho común europeo». ZIMMERMANN, Reinhard. Europa y el Derecho romano. Ed. Marcial Pons. Madrid, 2009. Págs. 119-120.

4 Metáfora tradicional para referirse a estos dos poderes tomada del Evangelio de San LUCAS («Dómine, ecce gladii duo hic»). LUCAS, San. Evangelio, 22, 38 en Sagrada Biblia. Santos Evangelios. Ed. EUNSA. Pamplona, 1983. Pág. 1.032.

5 Que el Estado moderno nazca como reacción secularizadora al orden imperial medieval, no quiere decir, sin embargo, que durante el medioevo no existiera una conceptual separación entre lo espiritual y lo temporal. Jorge de ESTEBAN, ha analizado el siguiente fenómeno, con estas palabras:

«Si la Europa cristiana, en sus regiones occidentales, "inventó» el Estado, se debe a que comenzaron a definirse las relaciones entre estos dos ámbitos diferenciados a partir de la Edad Media.

Su origen remoto se puede situar en la respuesta de Jesucristo, interrogado sobre la obligación de pagar los impuestos al emperador romano: "Dar al César lo que es del César y a Dios lo que es de Dios». Tal diferenciación será desarrollada más tarde en el siglo IV por San Agustín, distinguiendo entre la Ciudad de los hombres y la Ciudad de Dios, contraponiéndose así esta idea, por ejemplo, a la confusión típica del islamismo, que en lo sagrado y lo profano se mezclan indisolublemente».

ESTEBAN, Jorge de. Jaque al Estado. Ediciones libertarias. Madrid, 2000. Pág. 25. 
del Papa. El proceso emancipador iniciado por Maquiavelo mantiene así una función directamente secularizadora de las estructuras de la comunidad política y del nuevo Stato, apartándolo de cualquier tutela imperial y pontifical e, incluso, de toda pauta moral.

Esta nueva función secularizadora del Estado y de reacción frente al poder espiritual, tratará el ejercicio del poder político como una de las nuevas ciencias físicas exaltadas por la emergente cultura renacentista, instruyéndose esta nueva ciencia política en el método empírico y en el análisis científico de la praxis histórica como mejor medio para la objetivación y la desvinculación del Estado de toda tutela metapolítica. Y, en paralelo, y de un modo ciertamente paradójico, pretendiendo en este mismo proceso la asunción para el Estado de todo el poder religioso, no ya por su dimensión trascendente al hombre en cuanto que ser espiritual sino en cuanto que instrumento de acción gubernativa útil al gobierno del Príncipe absoluto ${ }^{6}$ Ma-

6 Nicolás MAQUIAVELO, en el capítulo XXI de su obra El Príncipe, ensalza, a Fernando el Católico, Rey de Aragón, a propósito de su hábil manejo de la religión instrumentalizada para sus fines políticos:

"Pudo sostener ejércitos con el dinero de la Iglesia y del pueblo, y adiestrar mediante esta larga guerra unas tropas que, posteriormente, siempre le proporcionaron gran honra. Además de esto, para poder emprender proyectos de más envergadura, sirviéndose siempre de la religión, con piadosa crueldad, expolió y expulsó de su reino a los marranos*: difícil encontrar un ejemplo tan singular como deplorable. Atacó también bajo el manto de la religión, África; realizó la campaña de Italia y, últimamente, ha atacado Francia». MAQUIAVELO, Nicolás. El Príncipe. Col. Ciencia Política. Ed. Istmo. Madrid, 2000. Págs. 142-143.

*En esta expresión se advierte, lamentablemente, un claro antisemitismo de Nicolás MAQUIAVELO, que en lugar de referirse simplemente al pueblo judío o a los judíos conversos al cristianismo, emplea una despectiva expresión popular para referirse a este colectivo. Esta expresión es igualmente advertida en el Diccionario de la Lengua Española editado por la Real Academia Española, que en su edición de 1992 recoge a la voz «marrano, na» la siguiente definición: «5. Aplicábase como despectivo al converso que judaizaba ocultamente», acepción del término a la que se refería en este caso MAQUIAVELO. Y todo ello para ensalzar la mencionada política religiosa del Rey Católico pues, "El 31 de marzo de 1492 los Reyes Católicos decretaron la expulsión de los judíos ante las presiones del Inquisidor Torquemada. Sólo los hebreos próximos a los reyes se convirtieron. Por otro lado, los verdaderos beneficiados del expolio fueron los súbditos de los reyes, que se aprovecharon de la venta forzosa de los bienes y haciendas de aquellos».

MAQUIAVELO, Nicolás. El Príncipe. Col. Ciencia Política. Ed. Istmo. Madrid, 2000. Pág. 143. Nota 103.

Del propio modo, otras ediciones recientes de «El Príncipe» de MAQUIAVELO, traducen este despectivo término empleado por MAQUIAVELO como aplicable no al pueblo judío sino a los «moros». Tal es el caso de la edición de El Príncipe con Estudio preliminar de FERNÁNDEZ CAMPO e Introducción de GONZÁLEZ-BLANCO de Ed. Styria. Madrid, 2009. Pág. 343. Otras ediciones aplican tal término a ambos grupos religiosos, "Es decir, los hebreos y los moros convertidos por la fuerza al catolicis- 
quiavelo emancipa así al Estado de toda tutela espiritual pero, necesariamente también, monopoliza para el Estado e instrumentaliza para el gobernante todo el poder religioso en el seno de la comunidad, en cuanto que útil a este poder gubernativo de su Príncipe. La aparentemente radical confesionalidad de los Estados en la Europa de las guerras de religión y de las Monarquías absolutas, ocultaba así que la construcción del Estado moderno había nacido de un proceso secularizador que había instrumentalizado la religión, por los emergentes principados europeos, contra la imposición de una respublica christiana incompatible con el absolutismo y con las demandas de las nuevas Monarquías nacionales; movimiento que pretende asumir para el Monarca un monopolio del otrora poder pontificio al que ahora se llamará libertad religiosa.

La Europa de las nuevas naciones y de los conflictos religiosos armados, la Europa de la libertad religiosa de los antiguos, configura así esta libertad no solo como un elemento caracterizador de la identidad nacional, sino, de hecho, como un elemento inherente a la soberanía política e incluso tipificador de la existencia de algunos nuevos Principados. El concepto de libertad religiosa se encuentra así presente en la teoría y en la praxis política europea de forma irreductible desde la génesis misma del concepto de Estado.

Tras el hallazgo de Nicolás Maquiavelo en la Italia renacentista, se producirán dos nuevos acontecimientos que consolidarán el proceso secularizador iniciado por el pensador florentino. En primer lugar, en el año 1517, un fraile agustino, Martín Lutero clavará en la Iglesia del Palacio de Wittenberg sus noventa y cinco tesis para la reforma de la Iglesia, desafiando la autoridad espiritual del Sumo Pontífice y haciendo saltar por los aires la unidad religiosa de ese Imperio cristiano que los Austrias españoles se empeñaban en mantener artificialmente intacto contra el reloj de la Historia. Resulta paradójico advertir cómo es un aventajado hijo espiritual de Agustín de Hipona, quien, precisamente, dará el golpe de gracia al agustinismo político en Europa. El segundo de estos grandes acontecimientos, ocurriría sólo décadas después en la monárquica Francia de 1576 de la mano del jurista Juan Bodino que tipificaría en sus Seis Libros de la República los caracteres de esa nueva plenitudo potestatis frente al Emperador y al Papa que desde entonces conocemos con el nombre de Soberanía.

mo», tal como sucede en la edición traducida por Roberto RASCHELLA de Ed. Losada. Buenos Aires, 1996. Pág. 186. Nota 297. Otras ediciones de esta obra en italiano como la preparada por Tommaso BAVARO, se refieren, simplemente a los «infedeli». Ver MACHIAVELLI, Niccolò. Il Principe. Ed. Mursia. Milano, 1995. Pág. 123. 


\section{2.- La Reforma protestante y la absolutización del Estado moderno: desvinculación del Estado del poder espiritual y asunción para el Estado del poder religioso.}

El proceso iniciado con la Reforma protestante, sustancialmente secularizador de la vida política del occidente europeo aunque formalmente confesional, originaría importantes consecuencias teóricas y prácticas para el devenir histórico de la vieja Europa. Para el hombre antiguo, mejor se defiende su libertad religiosa, cuanto mejor y más claramente se afirma la identidad religiosa de su Príncipe, lo mismo dentro del Estado que en el seno de una naciente comunidad de naciones. Esta deriva intelectual, además de cruentos y largos conflictos con el trasfondo de la religión -y de la asunción por los Monarcas de la cabeza de las Iglesias ${ }^{7}$ nacionales en muchos casosinició una espiral hacia el absolutismo y la plenitud de potestad, también en lo religioso, de las nuevas Monarquías europeas ${ }^{8}$.

Media Europa reformada se entrega así al protestantismo como emblema de nueva independencia frente al Imperio y al Papa, mientras la otra media, aún fiel al primado católico de Roma, se entrega a la profesión del derecho divino de los reyes y al ideal del regalismo

Sobra, manifestar que no compartimos, en absoluto, ni el despectivo término empleado por el florentino, ni el desprecio con el que MAQUIAVELO se dirige a este o a estos grupos religiosos y que, sin embargo, hemos preferido respetar junto con el conjunto de los autores, para que pueda apreciarse en toda su crudeza el sentir maquiavélico acerca de estas etnias y credos religiosos.

7 Refiriéndose al caso inglés y a la asunción legal de todo poder religioso en Inglaterra por parte del Monarca señala PEREIRA MENAUT:

«La reforma anglicana y la Act of Supremacy fueron parte de un proceso de acumulación de poder que culminaría en la soberanía o supremacía del Parlamento con la Corona».

PEREIRA MENAUT, Antonio Carlos. El ejemplo constitucional de Inglaterra. Ed. Servicio de Publicaciones de la Facultad de Derecho de la Universidad Complutense de Madrid. Madrid, 1992. Pág. 52.

8 Como ha señalado el Profesor FERNÁNDEZ-MIRANDA:

"La ruptura de la unidad de conciencia con la Reforma servirá, en un principio, al poderoso movimiento hacia la construcción del Estado Moderno que, lejos de apartar la religión del orden político, supondrá una exacerbación intolerante de la utilización del vínculo religioso como factor de integración política y una agudización regresiva en la confusión entre poder temporal y poder espiritual. Las teocracias calvinistas de Ginebra y Massachussets, despóticas e inquisitoriales, son un claro ejemplo; pero también en la Alemania luterana vemos resurgir instituciones de sabor medieval como el ius reformandi, ius recipiendi $y$ el ius reprobandi».

FERNÁNDEZ-MIRANDA CAMPOAMOR, Alfonso. «Estado laico y libertad religiosa». Revista de la Facultad de Derecho de la Universidad Complutense de Madrid. Número 54. Verano, 1978. Pág. 7. 
como instrumento para equilibrar el poder político de los Príncipes católicos con el de los nuevos Príncipes protestantes. Se instaura así en todas las nuevas Monarquías nacionales una nueva libertad religiosa, derivando todas las Monarquías absolutas hacia un único modelo de absolutismo en lo político y de formal integrismo -católico o protestante- en lo confesional. Todos los Reyes absolutos se sirven del origen divino de su poder ${ }^{9}$ como mecanismo de legitimación de su plenitudo potestatis, tal como sucedería en la Inglaterra de los Estuardo, en la Francia de los Borbones o en España de los nietos del Rey Sol, alcanzando de facto todos los Monarcas europeos un muy similar estatuto absolutizado y unos medios perfectamente análogos para el ejercicio nacional e internacional de sus poderes.

El Estado nace así desde su misma génesis como un verdadero proceso secularizador en el que, curiosamente, se desafía el poder espiritual del Pontífice a través de la exaltación del origen divino del poder del monarca ${ }^{10}$, identificando las naciones su libertad política con su libertad religiosa, esto es, con la lícita posibilidad de apartarse de las tesis universales del Imperio y del Papado abrazando colectivamente el culto confesado por su Príncipe soberano ${ }^{11}$ y monopolizando

9 El principal título encontrado por los monarcas para combatir la primacía del Emperador en lo político y del Pontífice en lo espiritual y para exaltar el origen, también divino, de su poder soberano fue un texto escrito por San PABLO en el capítulo XIII de su Epístola a los Romanos donde el apóstol afirmaba:

"Omnis anima potestatibus sublimioribus subdita sit: Non est enim potestas nisi a Deo: quae autem sunt, a Deo ordinate sunt. Itaque qui resistit potestati Dei ordinationi resistit. Qui autem resistant, ipsi sibi damnationem acquirunt».

PABLO DE TARSO, San. Epístola a los Romanos. Capítulo XIII. En Nuevo Testamento. Ed. Rialp. Madrid, 1986.

10 Señala el Profesor NEGRO PAVÓN cómo:

"La ruptura específicamente moderna de los siglos XVI y XVII fue fundamentalmente religiosa. La neutralización de la religión implicó la abolición de la autoridad espiritual y esto último conllevó a su vez. la desjerarquización general que descompuso el orden antiguo al decaer la Iglesia y el Imperio, y, al mismo tiempo, una relativa inversión de la articulación entre lo divino y lo humano. A pesar de ello, resulta enteramente coherente que el decisionismo moderno tuviese un primer apoyo en el derecho divino. Este derecho monárquico significaba conservación y comprensión del lazo entre lo divino y lo humano, así como un cierto orden que aún permitía restablecer y legitimar la jerarquía indispensable coordinada por el monarca, mientras se preparaba la despersonalización total del poder politico».

NEGRO PAVÓN, Dalmacio. La tradición liberal y el Estado. Unión Editorial. Madrid, 1995. Pág. 157.

11 Expresan perfectamente esta idea los Profesores LUCAS VERDÚ y LUCAS MURILLO DE LA CUEVA cuando a propósito de la misma afirman:

«El desarrollo de la creencia sobre el carácter vicario, o lugartenecial, del monarca respecto a la Divinidad romperá el concepto medieval de la Iglesia universal favoreciendo el nacimiento de Estados nacionales. El protestantismo al negar toda relación entre 
para el poder de este una multitud de beneficios relativos, por ejemplo, a la provisión de los oficios eclesiásticos en el territorio de su Reino.

La llamada Reforma protestante ${ }^{12}$, supuso así un movimiento de raíz teológico-religiosa que implicó desde su nacimiento mismo un fortísimo condicionante, no solo para la evolución de la historia política de Europa o para la evolución de la teoría del Estado sino, en rigor, para la aparición de un orden político nuevo cuyo paradigma político sería el Estado nacional y cuyo paradigma social sería el capitalismo ${ }^{13}$. La libertad de religión será así un detonante principal para la construcción de la nueva estructura política edificada contra el orden medieval, lo mismo o más que las doctrinas de Nicolás Maquiavelo sobre el ejercicio autónomo del poder o las de Juan Bodino sobre la soberanía. La protección de Maquiavelo a la autonomía del Estado y la protección de Lutero a la autonomía de la conciencia del Príncipe, unidas al deber del Pueblo de abrazar colectivamente la fe del nuevo Monarca, incluso contra la autoridad del Papa ${ }^{14}$, sentarán las bases morales para la ruptura de la unidad política y de la unidad religiosa medieval y de la conversión del poder religioso en una simple faceta del poder temporal.

Dios y el Pontífice, echó de menos la ausencia de un contacto con alguna persona o institución intermediaria entre Dios y el Estado. Lo centrará en el monarca reinante, jefe, además, en Inglaterra, de la Iglesia establecida».

LUCAS VERDÚ, Pablo y LUCAS MURILLO DE LA CUEVA, Pablo. Manual de Derecho Político. Volumen I. Ed. Tecnos. Madrid, 1994. Pág. 43.

12 En realidad, como afirma el Profesor TEJERO las tesis eclesiásticas propuestas por Lutero para reformar la Iglesia en la práctica subordinaban de forma necesaria lo espiritual a lo histórico, tesis incompatible con el carácter espiritual e intemporal del catolicismo. Así, como señala este autor:

"En el ámbito canónico, las tesis luteranas envolvían una serie de negaciones básicas que, por rechazar la naturaleza jerárquica de la Iglesia, el primado del Papa, la configuración de la Iglesia por los sacramentos y la posibilidad de las buenas obras, redujeron el orden jurídico del Pueblo de Dios a simples relaciones contingentes, derivadas de situaciones históricas cambiantes, cuya entidad no cabría calificar, en ningún caso, como valores de orden divino, sino solo como fruto de mudables circunstancias históricas». Pág. 91.

TEJERO, Eloy. Manual de Derecho Canónico. Ed. EUNSA. Pamplona, 1991.

13 WEBER, Max. La ética protestante y el espíritu del capitalismo. Ed. Península. Barcelona, 1998.

14 Expresa LUTERO de forma particularmente clara esta idea en su obra Von der Freiheit eines Christenmenschen («La libertad del cristiano») señalando:

"En este sentido amonesta el apóstol Pablo a los cristianos a someterse al poder secular, dispuesto siempre a prestarle su servicio, mas no con miras de alcanzar justicia, sino para servir libremente a los demás y a la autoridad secular, obedeciendo con amor y libertad».

LUTERO, Martín. La libertad del cristiano. 1520. Epígrafe 28. 
La libertad religiosa de los antiguos, como vemos, tiene el común denominador de su afirmación política colectiva, nunca individual, lo mismo en los Reinos católicos que en los nuevos Reinos reformados. Cuius regio, eius religio, fue el único punto en el que, de acuerdo con la mentalidad de su siglo, católicos y protestantes supieron ponerse de acuerdo ${ }^{15}$ de una forma recíprocamente comprensible y mutuamente transigible, pues la libertad religiosa de los antiguos derivaba intelectualmente de su pertenencia a una comunidad y de su identificación con ella. Así, al igual que en la identificación con la dinastía cifraba el pueblo su principal manifestación de libertad política, de la profesión del credo de su Príncipe nacía para los europeos antiguos la principal manifestación de su libertad religiosa. Quedará así en toda Europa a la conciencia del Príncipe la elección de la religión de su pueblo y, más que el deber, el derecho de su pueblo de abrazarla frente a los postulados dogmáticos del Papa.

\section{III.- LA PARADOJA DE LA RAZÓN DE ESTADO: ABSOLUTIZACIÓN DEL ESTADO Y ABSOLUTIZACIÓN DE LA RELIGIÓN.}

La libertad religiosa, como hemos visto, se identificó durante un largo periodo histórico con la confesionalidad del Estado llegando a convertirse en una faceta más del orden político, adquiriendo la religión en algunos aspectos el status de verdadera razón de Estado. Las nuevas tesis de la razón de Estado, extendidas primero por la Europa protestante e incorporadas enseguida a la praxis política de las Monarquías católicas, especialmente en la Francia de los Luises y de los cardenales validos, puso el interés político autónomo y objetivo del Estado por encima de cualquier otra razón humana o divina, llegando a convertir, paradójicamente, un Estado jurídicamente confesional y eclesiástico, en un Estado de facto agnóstico. Paradójicamente también, la nueva condición de actor religioso del Monarca en las Iglesias reformadas, determinará una formal exaltación religiosa del trono ${ }^{16}$ que ocultará tras de sí una sustancial

15 Así lo pone de manifiesto el Profesor MARTÍNEZ-TORRÓN, afirmando que "(...) en toda Europa, los Estados nacionales se construyeron al hilo de análogas interpretaciones del principio cuius regio eius et religio»

MARTÍNEZ-TORRÓN, Javier. "Transición democrática y libertad religiosa en España». Revista Persona y Derecho. Número 53. Ed. Servicio de Publicaciones de la Universidad de Navarra. Pamplona, 2005. Pág. 187.

16 Así, dirá BAGEHOT a propósito del Rey de Inglaterra:

«El rey para ellos, era el «ungido del Señor» y ningún otro poder tenía un carácter sagrado. El Parlamento, las leyes, la prensa, no eran más que instituciones humanas, mientras que la monarquía era una institución divina (...)». 
subordinación de la religión a los intereses políticos nacionales. Puede que nunca se haya observado una divinización más rígida del Monarca que durante el periodo absolutista de las Monarquías europeas, a la par que pocas veces se ha subordinado la religión, de una manera tan evidente al interés político del Estado ${ }^{17}$, como pronto demostraron la construcción del anglicanismo estatal en la Inglaterra de Enrique VIII o de la centralización del poder real en la católica Francia de los Luises. La doctrina política de la razón de Estado, penetrada así de una cierta deificación religiosa de la persona del Monarca produjo, sin embargo, un régimen político ignorante de cualesquiera intereses religiosos que no fuesen los políticos nacionales, radicalmente incompatibles con el viejo ideal imperial fundado en el universal catolicismo que aún pretendían alargar en el tiempo los Austrias españoles en franca oposición al signo de los tiempos. Oposición que solo sería vencida por la hábil diplomacia de Luís XIV de Francia que logró sentar a su nieto en el trono de España con la lógica oposición de la Casa de Habsburgo, que no tardaría mucho en ser vencida en el campo de batalla.

No tuvo así nada de particular, que en estas circunstancias germinase en España durante el reinado de los últimos Austrias, una Escuela de pensamiento aún enunciadora de tesis con vocación universal -al igual que su religión y su Imperio- abiertamente partidaria de la contrarreforma y que se convirtió casi ${ }^{18}$ en la única escuela europea de pensa-

BAGEHOT, Walter. La Constitución inglesa. Ed. Centro de Estudios Políticos y Constitucionales. Madrid, 2010. Pág. 52.

17 No resulta así difícil encontrar similitudes heredadas de aquella época entre el ceremonial sacro de consagración episcopal y el de entronización de un monarca absoluto. Donde el nuevo obispo recibe una mitra, el nuevo monarca recibe una corona, donde aquél recibe un báculo, este un cetro, donde el sacerdote una casulla, éste una capa, donde el obispo recibe una cátedra, el rey un trono, en tanto que ambos son ungidos con óleos sagrados en un templo o lugar de culto en consideración al origen divino de sus poderes.

18 La otra escuela abiertamente contraria al absolutismo monárquico nace de la obra de Juan ALTUSIO. Este autor, como en general el calvinismo militante negará de forma apriorística los postulados de cualquier doctrina política que atribuya el poder a un solo hombre. Para Altusio, la perfecta organización de la sociedad política es aristocrática y burguesa en la línea que triunfará en los cantones suizos. En su principal obra Politica methodice digesta, publicada en 1603, ALTUSIO se muestra abiertamente partidario de lo que hoy llamaríamos «organicismo social» como forma de integración de los poderes social y político. Acerca de la doctrina política de este autor dirá George Sabine: "El aspecto más importante de la doctrina de Altusio es el hecho de que hace residir la soberanía necesariamente en el pueblo como cuerpo. Éste no puede separarse de aquella porque la soberanía es una característica específica de tal tipo específico de asociación. En consecuencia, es inalienable y no pasa jamás a manos de una familia o clase gobernante. El poder se ejerce por los funcionarios administrativos de un estado, que son investidos de él por las normas jurídicas de tal estado». 
miento enfrentada al absolutismo estatal monárquico, al que identificaba con los «errores» teológicos de Maquiavelo y de Lutero. A través de un nuevo género de literatura política, los «consejeros de príncipes» ${ }^{19}$; se crea un innovador grupo de autores con intención política más que estrictamente religiosa, partidarios de una confesionalidad política del nuevo Estado a través de la confesionalidad del Príncipe como mejor forma de introducción de valores morales en la acción de gobierno ${ }^{20}$.

SABINE, George H. Historia de la Teoría Política. Fondo de Cultura Económica. México, D.F. Madrid, 1994. Pág. 326.

${ }^{19}$ Los autores calificables como arbitristas o consejeros de Príncipes son muchos. Ente los más importantes podemos citar además de a Pedro RIVADENEIRA, e incluso a muchos autores de la Escuela de Salamanca, a los siguientes:

Jerónimo CASTILLO DE BOVADILLA, con su «Política para corregidores y señores de vasallos»; Baltasar ÁLAMOS DE BARRIENTOS, con su «Suma de preceptos, justos, necesarios y provechosos en Consejo de Estado al Rey Felipe III, siendo Príncipe»; Tomás FERNÁNDEZ MEDRANO con su «Republica mixta»; Eugenio de NARBONA con su "Doctrina política civil escrita en aforismos»; Antonio de HERRERA con su "Primera parte de las varias epístolas, discursos y tratados de Antonio de Herrera a diversos claros varones, las cuales tienen muchas materias útiles para el gobierno político y militar»; Juan MÁRQUEZ con "El gobernador cristiano»; Juan de SANTA MARÍA, por el «Tratado de República y policía cristiana»; Fernando ALVIA DE CASTRO por la obra "Verdadera razón de Estado»; Lorenzo RAMÍREZ DE PRADO por "Consejo y consejero de príncipes»; Pedro BARBOSA HOMEM por sus "Discursos de la verdadera y jurídica razón de Estado»; Juan Pablo MÁRTIR RIZO por "Norte de príncipes»; Claudio CLEMENTE por "El maquiavelismo degollado»; Juan BLÁZQUEZ MAYORALGO por su «Perfecta razón de Estado» o Andrés MENDO por su obra «Príncipe perfecto y ministros ajustados».

Todos ellos citados por CASTILLO VEGAS, Jesús; MARCANO BUÉNAGA, Enrique; PEÑA ECHEVERRÍA, Javier y SANTOS LÓPEZ, Modesto. Todos ellos citados en: La razón de Estado en España. Siglos XVI-XVII Antología de textos. Col. Clásicos del Pensamiento. Ed. Tecnos. Madrid, 1998.

En algún sentido debe incluirse como autor político de estas fechas a Juan de MARIANA con su obra "Del rey y de la institución real» donde no se dedica a aconsejar príncipes sino a reflexionar la limitación del poder conveniente a la monarquía.

En nuestra opinión entre los tratadistas del arbitrismo y el consejo al Príncipe en España debe quedar también necesariamente incluso Diego de SAAVEDRA y FAJARDO por su «Idea de un príncipe político cristiano, representada en cien empresas». Tampoco podemos dejar de citar como arbitristas a otros geniales autores cuyo criterio político ha quedado eclipsado por su genio literario como son Francisco de QUEVEDO y VILLEGAS con su «Política de Dios, gobierno de Cristo y tiranía de Satanás»; Pedro CALDERÓN DE LA BARCA con su obra "El príncipe constante y esclavo por su patria» en la que exalta las virtudes del príncipe cristiano o Baltasar GRACIÂN en su obra "El político Don Fernando el Católico».

Fuera de España debemos citar también una preocupación por el consejo de Príncipes como remedio a los males del Estado, aunque de características no idénticas a la preocupación propia de la Escuela española. Corriente frecuentemente representada por Erasmo de ROTTERDAM en su obra "El Príncipe cristiano».

20 Sobre este particular ha señalado el Profesor NAVARRO-VALLS cómo estos valores «(...) ejercieron cierta influencia restrictiva sobre la autoridad del príncipe y de los funcionarios gubernamentales». 
Curiosamente, este nuevo género literario, formalmente opuesto a la razón de Estado -que por entonces significaba la emancipación teórica del Estado de cualquier tutela moral o de cualquier principio ético de gobierno- no logró acabar con esta razón de Estado como elemento caracterizador de un siglo, aunque lo que sí logró, decididamente, fue cristianizar esas «anticatólicas» tesis generalizadas en toda Europa por los «errores» del maquiavelismo ${ }^{21}$ y del protestantismo $^{22}$. Curiosamente, ante la imposibilidad de ir contra la corriente de un siglo, estos autores lograron la conversión al cristianismo de su enemigo político, la razón de Estado, originalmente condenada por la Iglesia Católica ${ }^{23}$. Así, lo paradójico de esta escuela es la cristianización de la razón de Estado según las doctrinas morales del catolicismo tridentino. Lo particular y al tiempo lo grande de su aportación, será así la síntesis lograda entre una vieja tradición intelectual española, profundamente imperial y, por tanto, decididamente partidaria de la religión católica universal, con el imparable signo absolutizador de las estructuras políticas del Estado que irremediablemente demandaban los tiempos. De una parte, es cierto que estos autores se manifiestan aún claramente partidarios de la confesionalidad católica del Estado -como mejor forma de introducción de pautas morales en el ejercicio del gobierno- aunque tienen también, indiscutiblemente, el mérito de ser los primeros autores de la Europa católica que aceptan, siquiera conceptualmente, la licitud de la existencia política del Estado y la ruptura de la respublica ch-

NAVARRO VALLS, Rafael. "Justicia constitucional y factor religioso». Anales. Revista de la Real Academia de Jurisprudencia y Legislación. Núm. 28. Madrid, 1998. Pág. 212.

21 El propio Quevedo en su "Politica de Dios, gobierno de Cristo y tiranía de Satanás» afirmará en el capítulo VI de su Parte II cómo "La materia de Estado fue el mayor enemigo de Cristo» y que "El más eficaz medio que hubo contra Cristo, Dios y Hombre verdadero, fue la razón de Estado», capítulo en el que desarrolla un verdadero tratado contra la razón de Estado con la que, según este autor, incluso llegó a tentarse a Cristo. 2010 .

Obra consultada en www.cervantesvirtual.com. Última consulta lunes 5 de abril de

22 Exponente de esta oposición es la obra de Francisco SUÁREZ «Defensio Fidei Catholicae adversus Anglicanae sectae errores» publicada en 1613.

23 Sin ir mas lejos, la Paz de Westfalia de 1648 fue duramente protestada por el Papa Inocencio X, cuyo pontificado se extendió entre 1644 y 1655, por consagrar la libertad religiosa de los Príncipes en algunas regiones de Europa, por afectar a los bienes de la Iglesia y por dar definitiva carta de naturaleza a un nuevo orden internacional al margen del tradicional agustinismo político. La protesta papal se formalizó a través de la Bula Zelo domus Dei, dictada el 26 de noviembre de 1648 por el mismo Pontífice que sería, poco después, genialmente inmortalizado por Diego Velázquez durante su segundo viaje a Italia. 
ristiana universal, al tiempo que exigen una conducta moral a toda acción del Estado. Autores tributarios, de una parte, de la tradición intelectual española y, de otra, del incipiente espíritu de la modernidad política y que cabalgan así en la irremediable tensión entre las exigencias teológicas de su Fe y las exigencias políticas de su siglo.

Puede que una de las más rotundas y a un tiempo clarificadoras afirmaciones hechas en este contexto intelectual para entender cuanto antecede, sea la sentencia del Padre Pedro Rivadeneira cuando en su «Tratado de la religión y virtudes que debe tener el Príncipe Cristiano para gobernar y conservar sus Estados, contra lo que Nicolás Maquiavelo y los políticos de ese tiempo enseñan», taxativamente, señalaba:

"Y porque ninguno piense que yo desecho toda razón de Estado (como si no hubiese ninguna), y las reglas de prudencia con que, después de Dios, se fundan, acrecientan, gobiernan y conservan los Estados, ante todas cosas digo que hay razón de Estado, y que todos los príncipes la deben tener siempre delante los ojos, si quieren acertar a conservar y gobernar sus Estados. Pero que esta razón de Estado no es una sola, sino dos: una falsa y aparente, otra sólida y verdadera; una engañosa y diabólica, otra cierta y divina; una que del Estado hace religión, otra que de la religión hace Estado (...)» 24 .

Formidable proclama del Padre Rivadeneira, condensadora del espíritu de un siglo y de la reacción española frente al protestantismo que continúa aún hoy siendo un elocuente exponente de la libertad religiosa de los antiguos, interpretada en este caso según el sentir del catolicismo tridentino. Doctrina católica de los hombres antiguos enunciada por la Escuela española que, sin embargo, supuso, paradójicamente, un gran avance y una insalvable transformación del pensamiento político en la medida en que tan conspicuo jesuita no niega ya, sino que acepta, las posibles bondades de la existencia política de un Estado, incluso de una razón de Estado que, mediante su cristianización, puede llegar a ser beneficiosa para la comunidad política. Actitud que, aunque al hombre moderno parezca hoy profundamente intransigente -al no separar las esferas espiritual y temporal del hecho religioso- dejaba entrever ya el espíritu de la modernidad política en la conciencia católica, en la medida en que aceptaba la posible bondad de una estructura política estatal cuyo nacimiento hubo acabado con el viejo Imperio cristiano me-

24 RIVADENEIRA, Pedro de. "Tratado de la religión y virtudes que debe tener el Príncipe Cristiano para gobernar y conservar sus Estados, contra lo que Nicolás Maquiavelo y los políticos de ese tiempo enseñan». Citado en PEÑA ECHEVERRÍA, Javier. Estudio Preliminar. La razón de Estado en España. Siglos XVI-XVII Antología de textos. Col. Clásicos del Pensamiento. Ed. Tecnos. Madrid, 1998. Pág. 11. 
dieval. En este sentido, el planteamiento de Rivadeneira es a la par que sempiternamente cristiano, al continuar abogando por la catolicidad de la estructura política, decididamente moderno, en la medida en que claramente acepta, asumiendo el signo de los tiempos, la compatibilidad de la existencia del Estado con la tradicional conciencia religiosa católica de los Monarcas españoles.

Como vemos, lo mismo en los Estados protestantes que en los Estados católicos, en Europa arraigó de forma generalizada aunque no simultánea gracias a la cuestión de la libertad religiosa, la nueva estructura política del Estado absoluto. Libertad religiosa que sería entonces entendida, exactamente a la inversa, de cómo tras las Revoluciones constitucionales, la entenderá el mundo contemporáneo.

\section{IV.- LA LIBERTAD RELIGIOSA DE LOS MODERNOS Y EL MOVIMIENTO CONSTITUCIONAL, O DE CÓMO NO HACER NI DEL ESTADO RELIGIÓN, NI DE LA RELIGIÓN ESTADO.}

\section{1.- La inmarcesible lección de Benjamín Constant al mundo contemporáneo.}

Para no romper esta tradición de importancia del factor religioso en la evolución política del Estado, los sucesos revolucionarios, especialmente los acaecidos en Francia en 1789, harán resurgir un nuevo espíritu en el que la que la religión tendrá también reservado un trascendental papel no ya solo en el Estado, sino ahora también en las conciencias -y consiguientemente en la acción política- de los nuevos ciudadanos que componen la recién nacida sociedad civil. El nuevo Estado constitucional partiendo de la realidad confesional del Estado absoluto, que este nuevo modelo de Estado aún tardará décadas en dejar atrás, tendrá por reto principal durante este siglo la construcción de la igualdad jurídica y política -mas no de una efectiva igualdad social y económica- a conveniencia de la nueva clase burguesa industrial y profesional que hubo inspirado la Revolución. Particularmente en materia religiosa, la revolución intelectual que supuso el pensamiento rousseoniano $^{25}$, unida al método racionalista kantiano, supuso una reformulación, por no decir una catarsis, de la libertad religiosa

25 No en vano, se ha señalado gráficamente por el Profesor NEGRO PAVÓN que KANT consideraba a Juan Jacobo ROUSSEAU «el Newton del mundo moral».

NEGRO PAVÓN, Dalmacio. La tradición liberal y el Estado. Unión Editorial. Madrid, 1995. Pág. 197. 
heredada del Estado absoluto. Libertad de religión cuyo ámbito natural dejó de ser el Estado para trasladarse a la nueva sociedad de hombres libres y, con ella, al ámbito de la conciencia individual de cada uno de ellos. El nuevo Estado kantiano, como entidad política articuladora de la sociedad a través de la legalidad ${ }^{26}$, tomará en amplia consideración el hecho religioso, como hecho de trascendente relevancia y significación social, mas no como una faceta de la soberanía del Estado, como hasta entonces se había hecho desde la génesis misma del Estado absoluto. Así, este tránsito -protagonizado por las doctrinas políticas y filosóficas de Juan Jacobo Rousseau e Immanuel Kant- supuso la verdadera liquidación de la libertad religiosa de los pueblos antiguos a la que Constant hiciera referencia en 1819 y la apertura de una nueva etapa de transición hacia la configuración jurídica y política de la libertad religiosa de los modernos.

El nuevo liberalismo, homogeneizador de toda estructura social y, al tiempo, refractario de toda intervención del Estado en la esfera de la nueva libertad individual de la ciudadanía burguesa, tuvo una de sus principales crisis, precisamente, en la determinación del alcance de la nueva libertad religiosa. Libertad religiosa que constituye para Constant una reveladora manifestación de la insalvable diferencia de la libertad política entre antiguos y modernos, habida cuenta de que para los antiguos «Todas las actividades privadas estaban sometidas a una severa vigilancia; nada se dejaba a la independencia individual, ni en relación con las opiniones, ni con la industria, ni, sobre todo, con la religión» al tiempo que «La facultad de elegir culto, que nosotros vemos como uno de nuestros derechos más preciados, les habría parecido a los antiguos un crimen y un sacrilegio» ${ }^{27}$. Ahora, en cambio, para los hombres modernos la tolerancia religiosa no es sino una exi-

26 El Estado inaugurado por Kant, que recoge la tradición de Rousseau, para el Profesor NEGRO PAVÓN:

«Es, como el de Hobbes, un espacio jurídico cuyo espacio estrictamente político, el de la soberanía, está organizado por el derecho público. Pero como Kant ordenó la sumisión al Estado de todo derecho, no solo el público, puesto que ha de ser estrictamente racional, una creación científica, su espacio es el de la sociedad entera. El Estado kantiano viene a ser la sociedad planificada por la legalidad-Kant estaba a favor del papel activo del Estado-, que tiene que ser portadora de la moralidad en el sentido de Rousseau y respetar, no obstante, la autonomía moral -la auctoritas particular-».

NEGRO PAVÓN, Dalmacio. La tradición liberal y el Estado. Unión Editorial. Madrid, 1995. Págs. 198-199.

27 CONSTANT, Benjamin. «De la libertad de los antiguos comparada con la de los modernos», en Escritos Políticos. Ed. Centro de Estudios Constitucionales. Madrid, 1989. Pág. 260. 
gencia de la convivencia civil que, como dirá este autor «no es otra cosa que la libertad para todos los cultos, presentes y futuros» 28 .

De esta forma desde la misma génesis del Estado constitucional en la Europa de las postrimerías del siglo XVIII y hasta el triunfo del constitucionalismo contemporáneo, el viejo continente se debate políticamente en el irreconciliable enfrentamiento entre un radicalismo civil (también llamado intolerancia civil, laicismo, agnosticismo, anticlericalismo o indiferentismo religioso del Estado) y otro radicalismo religioso integrista ${ }^{29}$ que aún se aferraba a la vieja idea del Estado confesional y se orientaba, como antaño -y sin duda por una inercia de siglos- más a la conquista política del Estado que a la conquista religiosa de las conciencias de los ciudadanos libres. Contexto de lucha política en el que ambas tendencias procuraron imponer al conjunto de la ciudadanía un régimen constitucional preceptivamente religioso o prescriptivamente agnóstico. Así, de forma intermitente y como trasfondo de casi todos los grandes acontecimientos normativos en Europa -muy especialmente durante la etapa de la codificación- se reproducen en todas las naciones, de modo transversal, una larga serie de debates reconducibles, de una u otra forma, al papel de la nueva libertad de religión en el seno de la convivencia ciudadana.

En este escenario, de un lado se defendían fervorosamente las radicales tesis del integrismo católico; y del otro, por un sector de la nueva burguesía liberal decididamente partidario de la abstención del Estado en materia comercial, profesional y patrimonial, se proponía ardorosamente la represión absoluta del hecho religioso de cualquier

28 CONSTANT, Benjamin. «Principios de Política», en Escritos Políticos. Ed. Centro de Estudios Constitucionales. Madrid, 1989. Pág. 257.

29 Ha señalado el Profesor FERNÁNDEZ-MIRANDA que durante los primeros pasos del Estado liberal «En este nuevo contexto, la Iglesia Católica seguirá manteniendo la tesis tradicional de la tolerancia como mal menor que generará una lógica desconfianza en todas las demás confesiones. Es preciso reconocer la incapacidad de la Iglesia para separar debidamente la beligerancia antirreligiosa de determinado laicismo liberal, de la posible fundamentación cristiana de la libertad religiosa; de distinguir la reprobación moral del indiferentismo religioso con que el liberalismo radical presentó la libertad de conciencia, de la proscripción jurídica y coactiva de la indiferencia o la disidencia; de diferenciar, como se haría con el tiempo, entre laicidad, como estatuto jurídico del Estado, y laicismo, como afirmación de una concepción de la vida. En el fondo hay una enorme dificultad para separar el objeto de la Moral y el objeto del Derecho, que si bien deben encaminarse a un mismo fin no cumplen la misma función».

FERNÁNDEZ-MIRANDA CAMPOAMOR, Alfonso. «Estado laico y libertad religiosa». Revista de la Facultad de Derecho de la Universidad Complutense de Madrid. Número 54. Verano, 1978. Págs. 8-9. 
esfera pública. Este nuevo modelo radical, no ya partidario de la interdicción de la confesionalidad estatal sino de la franca intolerancia religiosa de corte laicista vino a sustituir en el seno del Estado liberal la antigua intolerancia religiosa del Estado absoluto derivada de motivos teológicos, por una nueva intolerancia civil derivada de motivos revolucionarios. Esta intolerancia, como una nueva especie de razón de Estado por encima de la conciencia del individuo, fue duramente combatida, como contraria a la verdadera libertad revolucionaria por Benjamin Constant, por ser sustancialmente incompatible con el espíritu constitucional de la libertad de los modernos y con la nueva e indeclinable función protectora de la libertad individual encomendada al Estado.

Un indudable defensor de la libertad moderna como Constant reivindicará así con impecable brillantez esta nueva tercera vía de la religión en el seno del Estado constitucional que continúa, aún hoy, siendo una lúcida lección de Derecho constitucional, de sentido jurídico y de sentido común para los juristas contemporáneos. Durante esta primera etapa del constitucionalismo, el genio clarividente de Constant, fue así el primero en vislumbrar, exponer y defender, la necesidad de esta doble autonomía para la conciliación o mejor, para la integración en la vida ciudadana del credo religioso del individuo ${ }^{30}$. Constant será así el primero en oponerse tan decididamente a la confesionalidad como a la intolerancia religiosa del Estado constitucional defendiendo en materia religiosa un modelo constitucional conciliador, abierto y equilibrado -de forma análoga y coherente con la neutralidad que al nuevo Estado liberal se demandaba en relación con lo económico o lo social- que debería ser garantizando por el Derecho contenido en la nueva Constitución ${ }^{31}$.

Constant recordará triunfante a sus contemporáneos que «Hemos evitado asi el escollo de la intolerancia civil, con la que se ha querido sustituir a la intolerancia religiosa propiamente dicha, hoy que el

30 No en vano, señalará Constant la nula importancia del número de personas que profesen un credo como factor insignificante para su tolerancia o prohibición, habida cuenta de que, «(...) en materia de opinión, los derechos de la mayoría y los de la minoría son los mismos».

CONSTANT, Benjamin. «Principios de Política» en Escritos Políticos. Ed. Centro de Estudios Constitucionales. Madrid, 1989. Pág. 161.

31 «La constitución actual ha vuelto a la única idea razonable en relación con la religión, la de consagrar la libertad de cultos sin restricción, sin privilegios, sin obligar siquiera a los individuos, siempre que observen las formas exteriores estrictamente legales (...)».

CONSTANT, Benjamin. «Principios de Política» en Escritos Políticos. Ed. Centro de Estudios Constitucionales. Madrid, 1989. Págs. 158-159. 
progreso de las ideas se opone a esta última», ${ }^{32}$ al tiempo que se opone abiertamente a cualquier restricción de esta libertad religiosa que no sea estrictamente necesaria para el mantenimiento del orden público garantizado por la ley; e insistiendo en reprimir las conductas contrarias a este orden público por quienes practiquen la religión o sean ministros de ella no como conductas incluidas en el ámbito de la libertad religiosa o imputables al grupo confesional, sino como conductas reprobables y estrictamente reprochables de forma personal a sus autores ${ }^{33}$.

\section{2.- La evolución del Estado liberal hacia la quiebra de las democracias.}

En la recta final del Estado liberal clásico, el constitucionalismo sufrirá una etapa de gran desprestigio -curiosamente unida a nuevas oleadas de represión de la libertad religiosa- motivada, de un lado por la demanda radical revolucionaria del movimiento obrero de corte marxista y, por otra, por el auge de las ideologías totalitarias de corte fascista. El ascenso de estos regímenes determinará el nacimiento de nuevas leyes decididamente partidarias de la deificación del Estado y contrarias a la tolerancia religiosa -nuevamente por imponer un credo a los ciudadanos o por prohibirlos todos- que erradicarán la libertad de religión como el resto de las libertades ciudadanas conquistadas por la Constitución. En este contexto, la religión -cualquier religión- o bien se instrumentalizará descaradamente por el Estado como mecanismo de legitimación del poder temporal, o bien se considerará un fenómeno corruptor por razones étnicas o políticas, desde luego condenables y solo comprensibles desde una ciega óptica totalitaria.

La profesión de cualquier religión se considerará así un error como mucho tolerable en la esfera privada y, consiguientemente -y al igual que sucedía durante la etapa de los «errores» teológicos- al nuevo error civil o político del culto divino no se le concederán dere-

32 CONSTANT, Benjamin. «Principios de Política» en Escritos Políticos. Ed. Centro de Estudios Constitucionales. Madrid, 1989. Pág. 159.

33 "La autoridad nunca debe proscribir una religión, ni siquiera cuando la crea peligrosa. Que castigue las acciones culpables que una religión pueda cometer, pero no como actos religiosos, sino como acciones culpables».

CONSTANT, Benjamin. «Principios de Política» en Escritos Políticos. Ed. Centro de Estudios Constitucionales. Madrid, 1989. Págs. 177-178.

34 CONSTANT, Benjamin. "Principios de Política» en Escritos Políticos. Ed. Centro de Estudios Constitucionales. Madrid, 1989. Pág. 179. 
chos. Las nuevas filosofías políticas totalitarias de uno y otro signo y los intelectuales que las extendieron de forma cómplice con estos regímenes, interesadamente olvidaron aquel pensamiento de Benjamin Constant de que, "Error o verdad, el pensamiento del hombre es su propiedad más sagrada; error o verdad, los tiranos son igualmente culpables cuando lo atacan. Quien proscribe, en nombre de la filosofía, la superstición especulativa, quien proscribe, en nombre de Dios, la razón independiente, merece igualmente la condena de los hombres de bien».

Por lo demás, este lamentable período de tiempo en el que la libertad política se vio secuestrada por las dictaduras y Europa desangrada por la Guerra, en un proceso que en muchas de sus regiones solo se superaría en las postrimerías del siglo XX, poco puede interesar al Derecho constitucional; a no ser, una vez más, para constatar hacia dónde conducen irremediablemente la eliminación de la libertad civil y la pérdida de la moderación política.

\section{3.- La nueva libertad religiosa del constitucionalismo contemporáneo.}

Durante un apasionado y agitado siglo XIX que se prolongó durante el primer tercio del siglo XX, pese a las advertencias de algunos defensores de la libertad como Benjamín Constant, el constitucionalismo europeo buscó y no encontró de una forma definitiva el punto estable de conexión y convivencia política que unificase y sintetizase normativamente los expansivos intereses de las iglesias y el Estado. Punto de conexión al que se arribará a través de las constituciones democráticas de tercera generación que se promulgaron en la Europa de la segunda posguerra mundial, ya bien entrado el siglo XX. Tras la dramática experiencia europea de los años 30 y principios de los 40 , y de la vivencia de no pocas oleadas de represión cruenta de la libertad religiosa en las postrimerías del Estado liberal europeo primero y en la Europa de las dictaduras después, la conciencia colectiva de todas las democracias occidentales demandará no solo un nuevo papel del Estado en relación con la libertad de religión sino una reformulación de todas las viejas libertades liberales y, en general del modelo de Estado cuyo colapso derivó en el ascenso de las dictaduras y en el desencadenamiento de la Segunda Guerra Mundial. La reformulación de estas libertades afectaría también, de manera decisiva, a la construcción de una nueva libertad religiosa.

Desde un punto de vista constitucional, la nueva democracia social de masas se articuló manteniendo en pie el conjunto de libertades 
civiles y políticas heredadas del viejo Estado liberal, pero alterando sustancialmente la función del Estado respecto de las mismas. El papel del nuevo Estado social se orientaría así no solo a garantizar formalmente el ejercicio de los derechos, sino a promover las condiciones para que las libertades ciudadanas fuesen sustancialmente reales y efectivas. Y en estas coordenadas de cooperación entre la sociedad y el Estado, será también reformulado el derecho a la libertad religiosa de los ciudadanos ${ }^{35}$. La contemplación del lugar al que había conducido a Europa el olvido de la democracia y la lesión de las libertades civiles y políticas -entre ellas la libertad religiosa- unida a la necesaria conciencia de culpa por los horribles crímenes que en suelo europeo se hubieron cometido por motivos étnico-religiosos, hicieron el resto. La aparición del poder constituyente impulsó un gran cambio normativo en las nuevas declaraciones internacionales de derechos y en las nuevas normas constitucionales como reflejo de una conciencia general de necesidad de que la protección de la libertad religiosa pasase del ámbito de la conciencia individual a la conciencia colectiva. Conciencia que, justo es reconocerlo, no afectó solo al Estado sino al conjunto de las confesiones religiosas occidentales y que se fundó, por fin, también en la tolerancia de las confesiones religiosas. La Iglesia Católica, aceptará así el nuevo poder constituido en todos los Estados democráticos que, a su vez, reconocerán y garantizarán la autonomía de la Iglesia y de las demás confesiones religiosas. La configuración de la libertad religiosa de los modernos se articulará así como un derecho individual del ciudadano y como un bien jurídico protegido en cuanto que socialmente enriquecedor de la compleja y diversa sociedad de fines del siglo XX y principios del siglo XXI.

Como si -ahora sí- los juristas contemporáneos hubiesen escuchado las prudentes admoniciones de Constant, se mantuvo en pie la protección constitucional del derecho fundamental a la libertad de conciencia del individuo y, con ella, la de cada ser humano a confesar un culto di-

35 Refuerza esta idea el Profesor FERNÁNDEZ-MIRANDA que, a propósito de esta circunstancia ha afirmado cómo "Al igual que el conjunto de las libertades liberales, y el propio significado y alcance de la libertad, son estimados insuficientes por la conciencia de nuestro tiempo, lo mismo ocurre con la libertad religiosa reducida al libre juego de la espontaneidad social. La insuficiencia deriva de que la dimensión real de la libertad depende muy fundamentalmente de las situaciones sociales que permiten o imposibilitan su disfrute existencial como opciones reales».

FERNÁNDEZ-MIRANDA CAMPOAMOR, Alfonso. «Estado laico y libertad religiosa». Revista de la Facultad de Derecho de la Universidad Complutense de Madrid. Número 54. Verano, 1978. Pág. 15. 
vino o a no confesar ninguno. Pero se construyó ahora también una amable aconfesionalidad del Estado fundada en una necesaria neutralidad respecto del factor religioso -sin implicar, en absoluto, ignorancia o desprecio ${ }^{36}$ de este factor de evidente relevancia social- en el seno de las democracias pluralistas. Lo trascendente, así pues, fue el cambio de modelo de Estado hacia el Estado social y democrático de masas que, por sí mismo, trajo consigo una nueva articulación jurídica de la libertad de religión basada ya no en el abstencionismo, sino en la toma en activa consideración por el Estado del hecho religioso. Se configura así el nuevo deber constitucional del Estado de colaborar activamente con las diferentes confesiones religiosas presentes en la sociedad ${ }^{37}$, unido a los deberes de respetar el particular estatuto jurídico de cada una de ellas ${ }^{38}$, de facilitar los cauces de participación de estas confesiones en la vida social ${ }^{39}$; y todo ello sin que esa colaboración implicase lesión alguna de la laicidad estatal, confusión de la esferas de interés de ambas partes o lesión de la neutralidad religiosa del Estado.

36 CONSTANT, adelantándose al papel del Estado social, entre otras cosas, se mostró abiertamente partidario de que el Estado liberal colaborase en la financiación de cualquier confesión religiosa que tuviese una implantación social que lo hiciese aconsejable. Así, afirmaba:

"(...) desde el momento en que una secta llega a reunir alrededor de sus altares a un número considerable de miembros de la sociedad, esa sociedad debe subvencionar a la nueva iglesia. Al subvencionar a todas, el peso es igual para todos, y en lugar de ser un privilegio, es una carga común que se reparte equitativamente».

CONSTANT, Benjamin. «Principios de Política» en Escritos Políticos. Ed. Centro de Estudios Constitucionales. Madrid, 1989. Pág. 181.

37 Como ha señalado el Profesor NAVARRO-VALLS, «(...) es bien sabido que la verdadera religión suele ser un sólido fundamento de tolerancia» mientras que "Distinta cosa son los fenómenos sectarios o tendencias integristas, que han sido más bien un factor distorsionador y no de humanización y progreso».

NAVARRO VALLS, Rafael. "Justicia constitucional y factor religioso». Anales. Revista de la Real Academia de Jurisprudencia y Legislación. Núm. 28. Madrid, 1998. Pág. 215.

38 Puede que el estatuto jurídico más particular sea el de la Santa Sede que, por razones históricas y jurídicas perfectamente conocidas y justificadas, goza de personalidad jurídica internacional y territorio propios en la Ciudad del Vaticano, al menos desde los Pactos de Letrán de 11 de febrero de 1929. Este estatuto hace que los convenios que firma esta confesión religiosa con otros Estados adopten el estatuto jurídico de tratados internacionales.

39 A propósito de esta cuestión en Profesor FERNÁNDEZ-MIRANDA ha señalado como «De este modo cuando el Estado proceda a la remoción de obstáculos o a la concesión de facilidades para las actividades religiosas no estará, en el fondo, dialogando con las confesiones ni defendiendo sus intereses; estará dialogando con la sociedad que es el verdadero soporte humano de toda Iglesia».

FERNÁNDEZ-MIRANDA CAMPOAMOR, Alfonso. «Estado laico y libertad religiosa». Revista de la Facultad de Derecho de la Universidad Complutense de Madrid. Número 54. Verano, 1978. Pág. 18. 
La nueva configuración constitucional de la libertad religiosa en el Estado social se construyó así procurando evitar la rigidez de una dogmática regulación constitucional definitiva y agotadora de la cuestión religiosa -como había pretendido el Estado liberal- separando en su lugar, con acusado pragmatismo, las esferas estatal y eclesiástica de la vida ciudadana. Se garantizaron así a nivel constitucional la separación y la cooperación entre el Estado y las diferentes confesiones religiosas $^{40}$, al tiempo que fueron configurados por las nuevas Constituciones de forma simultánea, el derecho fundamental del individuo a la libertad de conciencia y el derecho de las comunidades a su autonomía en el seno del Estado. La cuestión religiosa se habría desplazado así definitivamente de la esfera política del Estado a esfera civil de la sociedad, en el seno de un nuevo modelo de Estado social cómplice de una estrecha colaboración con la sociedad y en constante atención a los actores de su cambiante y compleja realidad. El nuevo papel del Estado social será desde ahora siguiendo las proclamas de Benjamín Constant más de un siglo después de que éste las formulase, no solo el de garantizar la libertad religiosa y de culto del individuo, sino el de garantizar también la cooperación del Estado en materia religiosa con la sociedad y con las confesiones nacidas libremente ${ }^{41}$ en ella.

La libertad religiosa se configurará así como una nueva cuestión de índole exclusivamente social ${ }^{42}$ permanentemente abierta y tomada en consideración por las normas constitucionales no como compe-

40 Señala el Profesor NIETO NÚÑEZ, a propósito de la cooperación entre el Estado Español y la Santa Sede, constitucionalmente prevista en el artículo 16 de la Constitución Española de 1978 que: «(...) es en virtud de este mismo peso sociológico por lo que, al hablar de cooperación, se nombre a la Iglesia católica, sin que ello implique necesariamente violar el principio de igualdad jurídica, sino más bien una justa aplicación del mismo en reconocimiento de la realidad social».

NIETO NÚÑEZ, Silverio. «El modelo actual de cooperación entre el Estado y las confesiones religiosas». Anuario de Derecho Eclesiástico del Estado. Volumen XXIV. Ed. Ministerio de Justicia. Madrid, 2008. Pág. 52.

41 En definitiva, como señala el Profesor FERNÁNDEZ-MIRANDA, «Sin embargo, hay en el cristianismo una honda semilla de libertad personal y de respeto que la dominación temporal de la Iglesia desde el Edicto de Milán y la conciencia histórica medieval impidieron florecer».

FERNÁNDEZ-MIRANDA CAMPOAMOR, Alfonso. «Estado laico y libertad religiosa». Revista de la Facultad de Derecho de la Universidad Complutense de Madrid. Número 54. Verano, 1978. Págs. 7-8.

42 Como subraya FERNÁNDEZ-MIRANDA, «Será pues la sociedad, dinámica y variable, la que determinará en cada momento las diversas creencias vigentes que reclaman la protección estatal».

FERNÁNDEZ-MIRANDA CAMPOAMOR, Alfonso. "Estado laico y libertad religiosa». Revista de la Facultad de Derecho de la Universidad Complutense de Madrid. Número 54. Verano, 1978. Pág. 27. 
tencia del Estado, sino como una realidad más inherente al enriquecedor pluralismo de una sociedad civil de ciudadanos libres; y en cuanto que tal, jurídicamente protegida por la Norma Fundamental del Estado. Libertad individual protegida en la Constitución en su doble dimensión de titularidad jurídica individual y de irreductible ejercicio colectivo.

El constitucionalismo del Estado social, situado así entre la sociedad y el Estado, supuso la implantación de una suerte de pacto político de transigencia en materia religiosa, garantizador a un tiempo de la laicidad estatal y de la tolerancia religiosa social, que pronto -en términos históricos- recibiría la cobertura jurídica del Estado y la bendición de las confesiones religiosas cristianas ${ }^{43}$ que vieron así reforzada su autonomía frente al Estado. Autonomía que, en el contexto del siglo XXI y con un mundo cada día más pequeño, la Iglesia Católica sabiamente aprovechó -recordando su forma de hacer medieval- para operar una cierta transformación en el cauce de su mensaje evangélico articulando desde ahora la transmisión de su Fe, mucho más a través del vínculo personal que podía garantizarle la

43 En el caso de la Iglesia Católica, no cabe duda de la asunción de este modelo de separación de las esferas temporal y espiritual desde, al menos, la celebración del Concilio Vaticano II y, en concreto, desde que PABLO VI promulgara el 7 de diciembre de 1965 la Declaración «Dignitatis Humanae» sobre la libertad religiosa.

«2. Este Concilio Vaticano declara que la persona humana tiene derecho a la libertad religiosa. Esta libertad consiste en que todos los hombres han de estar inmunes de coacción, tanto por parte de individuos como de grupos sociales y de cualquier potestad humana, y esto de tal manera que, en materia religiosa, ni se obligue a nadie a obrar contra su conciencia, ni se le impida que actúe conforme a ella en privado y en público, sólo o asociado con otros, dentro de los límites debidos. Declara, además, que el derecho a la libertad religiosa está realmente fundado en la dignidad misma de la persona humana, tal como se la conoce por la palabra revelada de Dios y por la misma razón natural. Este derecho de la persona humana a la libertad religiosa ha de ser reconocido en el ordenamiento jurídico de la sociedad, de tal manera que llegue a convertirse en un derecho civil».

http://www.vatican.va/archive/hist_councils/ii_vatican_council/documents/vatii_decl_19651207_dignitatis-humanae_sp.html. (Última consulta de 4 de mayo de 2010).

No obstante, este principio de separación entre lo espiritual y lo temporal se cifra ya antes del Concilio Vaticano II en el éxito alcanzado por los Pactos lateranenses, cuyo modelo separador de la Iglesia respecto del Estado en Italia, habría garantizado a la Iglesia Católica y a sus fieles una verdadera libertad religiosa en un triple sentido individual, colectivo e institucional. "Por lo tanto, esos Pactos crearon escuela, y se exportó fuera de Italia un modelo jurídico destinado a tener un éxito generalizado». Así se pone de manifiesto en recientes publicaciones de la Iglesia Católica. Ver:

«Un modelo jurídico destinado a tener un éxito generalizado». L'Osservatore Romano. Edición semanal en lengua española. Año XLII, número 8 (2.147) - 21 de febrero de 2010. Pág. 4. 
conquista de una sociedad de hombres y mujeres libres que a través del vínculo institucional y territorial que podía garantizarle la conquista de un Estado soberano.

\section{4.- Una cuestión de actualidad: ¿laicidad o laicismo?.}

A punto de finalizar la primera década del siglo XXI, en medio del mundo de la globalización tecnológica, económica y humana se ha producido un inesperado y repentino replanteamiento de los problemas jurídicos relativos a la libertad religiosa en casi todos los Estados del mundo ${ }^{44}$ y, muy particularmente, el seno de los Estados constitucionales de cultura occidental.

En los ámbitos laboral, educativo, cultural, artístico y, en general, todo el tejido social occidental se ha visto penetrado de una nueva realidad en la que necesariamente conviven hoy hombres y mujeres -nacionales o extranjeros- de diferente origen geográfico, cultura, raza y credo religioso. La tentación, pues de los Estados del siglo XXI en relación con la libertad de religión puede ser de un lado la defensa social y normativa a ultranza de la cultura religiosa tradicional de cada Estado creando un clima social de hecho xenófobo con los credos recién incorporados a la sociedad; solución afortunadamente descartada por los Estados constitucionales. Y, de otro, la posibilidad de un jurídico desprecio a esa nueva realidad social multicolor, que se transmute en leyes de hecho intolerantes con toda manifestación pública del hecho religioso -a través de la articulación normativa de un laicismo ${ }^{45}$ militante- como nueva forma de razón de Estado por encima de la conciencia del individuo.

44 Sobre este particular, acierta el Profesor PALOMINO cuando apunta que «(...) por otro lado, la religión -unida a los masivos desplazamientos humanos- se presenta hoy en día como un potencial elemento globalizado transfronterizo sobre cuyas consecuencias todavía no hemos reflexionado bastante».

PALOMINO LOZANO, Rafael. «Libertad religiosa y libertad de expresión». Ius Canonicum. Revista del Instituto Martín de Azpilicueta. Facultad de Derecho Canónico. Universidad de Navarra. Volumen XLIX. Número. 98. Pamplona, 2009. Pág. 511.

Como advierte el Profesor FERNÁNDEZ-MIRANDA:

"La diferenciación entre laicismo y laicidad (laicisme y laicité), tiene su origen en los sectores liberales católicos franceses que abren una brecha en la concepción tradicional de la tolerancia tratando de hacer compatible la condena del laicismo de la filosofía racionalista, con la aceptación de la libertad de cultos y de la neutralidad del Estado».

FERNÁNDEZ-MIRANDA CAMPOAMOR, Alfonso. «Estado laico y libertad religiosa». Revista de la Facultad de Derecho de la Universidad Complutense de Madrid. Número 54. Verano, 1978. Pág. 12.

45 CONSTANT, Benjamin. «Principios de Política» en Escritos Políticos. Ed. Centro de Estudios Constitucionales. Madrid, 1989. Pág. 160. 
Dejemos que sea Constant quien, desde la indudable autoridad de sus palabras, solucione esta inquietud que nos es contemporánea con el mismo pensamiento que empleaba en los albores del Estado constitucional, cuando afirmaba que "La intolerancia civil es igual de peligrosa, más absurda y, sobre todo, más injusta que la intolerancia religiosa. Es igual de peligrosa porque conduce a los mismos resultados con otro pretexto; es más absurda porque no se basa en la convicción; es más injusta porque el mal que causa no lo hace por deber, sino por cálculo».

Edifiquemos pues, siguiendo a Constant, la verdadera libertad religiosa de los hombres y mujeres modernos; y, superando los errores del pasado, construyamos un siglo XXI verdaderamente democrático, social y constitucional en que no se haga ni del Estado religión, ni de la religión Estado. 
05-Jose María Cohelo 13/04/2011 12:41 Página 198 